\title{
Hi-PoAD technique for Adolescent Idiopathic Scoliosis in Adult: Personal case series
}

\author{
Cesare Faldini ${ }^{1} \cdot$ Francesca Barile $^{1}\left[\right.$ Fabrizio Perna $^{2} \cdot$ Stefano Pasini ${ }^{1} \cdot$ Michele Fiore $^{1} \cdot$ Giovanni Viroli $^{1}$. \\ Alberto Di Martino ${ }^{1}$. Alberto Ruffilli ${ }^{1}$
}

Received: 5 May 2020 / Revised: 13 April 2021 / Accepted: 8 June 2021 / Published online: 17 June 2021

(c) The Author(s) 2021

\begin{abstract}
Purpose The aim of this article is to present an original surgical technique for the treatment of rigid Adult Idiopathic Scoliosis (AdIS) and the results at minimum 2 years follow-up in a cohort of 40 patients.

Methods We retrospectively reviewed 40 patients affected by rigid AdIS, older than 40 years and operated with a posterior one stage surgical technique summarized with the acronym Hi-PoAD, (high-density pedicle screws, Ponte osteotomies, asymmetric rods contouring, direct vertebral rotation). The demographic and surgical data were collected, and the improvement of clinical scores and radiologic parameters was obtained after surgery, at 1 and 2 years and at final follow-up, to assess deformity correction, coronal and sagittal balance and clinical outcome.

Results The average follow-up was 2.9 years (range 2-3.5). Average coronal Cobb angle decreased from $65.0^{\circ} \pm 8.4$ to $18.9^{\circ} \pm 3.9(p<0.01)$. Rotation sagittal angle decreased from $26.2^{\circ} \pm 4.4^{\circ}$ to $12.4^{\circ} \pm 2.8^{\circ}(p<0.01)$. Mean thoracic kyphosis improved from $23.1^{\circ} \pm 3.6^{\circ}$ to $36.0^{\circ} \pm 3.9^{\circ}$. SRS-22 improved form $2.9 \pm 0.4$ to $3.7 \pm 0.6(p<0.01)$. Four early post-operative deep wound infections were observed, all healed after debridement and implant retention. No mechanical complication, junctional kyphosis, deformity progression or non-union were recorded at the last follow-up.

Conclusions $\mathrm{Hi}-\mathrm{PoAD}$ technique proved to be safe and effective in the treatment of rigid Adult Idiopathic Scoliosis. The reason for the success is related to the combined strategies adopted, that dissipates corrective forces over several levels, reducing mechanical stress at the screw-bone interface and optimizing corrective potential.
\end{abstract}

Keywords Scoliosis · Adolescent idiopathic scoliosis in adult $\cdot$ Scoliosis treatment $\cdot$ Scoliosis technique

\section{Introduction}

Adult Idiopathic Scoliosis (AdIS) is as an Adolescent Idiopathic Scoliosis (AIS) of the thoracic and/or lumbar spine which progresses in adult life (Aebi type 2), usually combined with secondary degeneration and/or imbalance [1]. Despite adult life is defined as starting at the end of the growing period, the strategies of surgical correction of AdIS can be effectively inspired from those adopted in AIS in the

Francesca Barile

Francesca.barile@ior.it

1 Department of Biomedical and Neuromotor Science - DIBINEM, University of Bologna, 1st Orthopaedic and Traumatologic Clinic, IRCCS Istituto Ortopedico Rizzoli, Bologna, Italy

2 Dipartimento Rizzoli Sicilia, IRCCS Istituto Ortopedico Rizzoli, Bagheria, Italy second and third decade of life [2]. The main features of Aebi type 2 AdIS usually occur from the fourth decade of life with worsening of the main curve (in terms of angular value, as well as stiffness) and structural changes of compensatory curves [3]. Correction strategy in this population of patients should consider these features with highlighted differences with respect to AIS [4, 5]: for this reason, we assumed that distributing corrective strength through a combination of different manoeuvres may result in enhanced clinical and radiographical results alongside a low rate of complications in patients over 40 years with rigid AdIS.

The aim of this article is to describe the innovative posterior one stage surgical technique summarized with the acronym $H i-P o A D$, which consists of simultaneous application of different surgical strategies, all well described individually, as high-density screwing [6-9], Ponte osteotomies [10-13], asymmetric rods contouring [14-16], direct vertebral rotation (DVR) [17] in the treatment of rigid AdIS (with less 
than $25 \%$ of correction at bending supine radiographs), the complication rate and the clinical and radiographical results obtained at minimum 2 years follow-up (FU) in a cohort of 40 patients over 40 years treated.

\section{Materials and methods}

\section{Study sample}

A retrospective review of patients over 40 years old with rigid AdIS who underwent surgery with $H i$-PoAD technique was undertaken.

Follow-up evaluations were performed post-operatively, at 1 and 2 years and up to final follow-up. Informed consents for participation in the study and for publication of clinical images were obtained from each patient.

\section{Data collection}

The patients enrolled were all affected by AdIS of the thoracic and/or lumbar spine, with less than $25 \%$ of reduction in the main curve. Patients with lack of flexibility due to anterior vertebral bony fusion (congenital or acquired) evaluated by routinely performed pre-operative MRI were excluded from the study.

Operative time, blood loss, length of stay, intra- and postoperative complications were recorded. Coronal Cobb's angle of each curve, coronal flexibility (difference in Cobb's angle of the main coronal curve between the pre-operative full-length standing and lateral supine side-bending X-rays, expressed as a percentage), thoracic kyphosis (TK) and lumbar lordosis (LL) angles were measured on pre- and postoperative full-length standing and lateral side-bending radiographs. C7 plumb line (C7PL)/central sacral vertical line (CSVL) and sagittal vertical axis (SVA) were used to assess coronal and sagittal imbalance. The rotation angle sagittal (RAsag) was calculated in the 22 patients whose pre- and post-operative CT-scans were available. SRS-22 questionnaire was administered pre-operatively and at last follow-up.

\section{Surgical planning}

A surgical planning was performed on pre-operative radiographs in order to assess the fusion area, the correct levels for Ponte osteotomies and the rods contour.

The fusion area was pre-operatively defined according to the criteria by Lenke et al. [18]. In the presence of disc degeneration at the level distal to the planned lower instrumented vertebra (LIV) and when compensatory curves showed low flexibility, the fusion area was extended distally.

The first Ponte osteotomy was planned at the apex of the main curve and at the two periapical levels (above and below the apex) in all cases. Further extension proximally and distally was performed in all the curves with a Cobb angular value over $70^{\circ}$. When osteotomies were planned distal to T12, they were performed according to Smith-Petersen.

The rods were asymmetrically moulded, to obtain a synergic action on sagittal profile restoration, with a lifting effect at the physiological apex of thoracic kyphosis and a lowering effect in the lumbar spine to restore lumbar lordosis; at the scoliosis apex, the concavity rod was higher (over-bended) than the convexity rod in order to obtain a derotational effect (Figs. 1, 2, 3 and 4).

\section{Surgical technique}

All surgeries were performed by the first author. Patient was placed prone on the Allen table with multimodal evoked potentials neuromonitoring. Subperiosteal exposure of the posterior elements was performed. The inferior articular facets were excised at every level of the desired fusion area, to allow spinal release and increase spinal flexibility with the exception of the two most cephalad instrumented vertebrae to reduce the risk of proximal junction syndrome. A 2.7$\mathrm{mm}$ drill hole was performed at every level included in the fusion area adopting a funnel technique in the thoracic tract. In presence of type $C$ and D pedicles [19], an in-out-in trajectory was chosen. The drilled tract was tapped for $1.5 \mathrm{~cm}$ with tap smaller than the screw diameter (e.g. $3.5 \mathrm{~mm}$ for a $4.5 \mathrm{~mm}$ screw).

With the aim of optimizing force transmission from the tulip to the screw, uniplanar pedicle screws (K2M® MESA ${ }^{\circledR}$ Stryker) were adopted in 24 cases, while polyaxial lockable screws (Must ${ }^{\circledR}$, Medacta ${ }^{\circledR}$ ) were used in 16 cases. At T12, given the more medial entry point at this level, a polyaxial screw was always chosen to facilitate rod engaging in the tulip. Ponte osteotomies were then performed according to the pre-operative planning with resection of the spinous process, removal of the residual superior facets, wide inferior and superior laminectomies with the removal of the entire ligamentum flavum extending from pedicle to pedicle to promote release in concavity and compression in convexity.

Two different $5.5-\mathrm{mm}$ cobalt-chrome rods were then asymmetrically moulded (with the convexity rod less bended than the concavity rod), placed through the crickets $\left(\mathrm{K} 2 \mathrm{M} \circledast{ }^{\circledR}\right.$ MESA ${ }^{\circledR}$ Stryker) or through the locking towers (Must ${ }^{\circledR}$ Medacta $\left.{ }^{\circledR}\right)$ and simultaneously rotated with the curves consensually oriented on the sagittal plane. Extensors were applied over the crickets or the locking towers at periapical levels both in concavity and in convexity and direct vertebral rotation was performed. Maintaining a derotative force applied over the extensors, the translation manoeuvre was performed progressively, tightening the crickets or the locking towers. This allowed to sum the corrective power of DVR to that offered by translational manoeuvre over differently moulded rods. The translation manoeuvre over the 


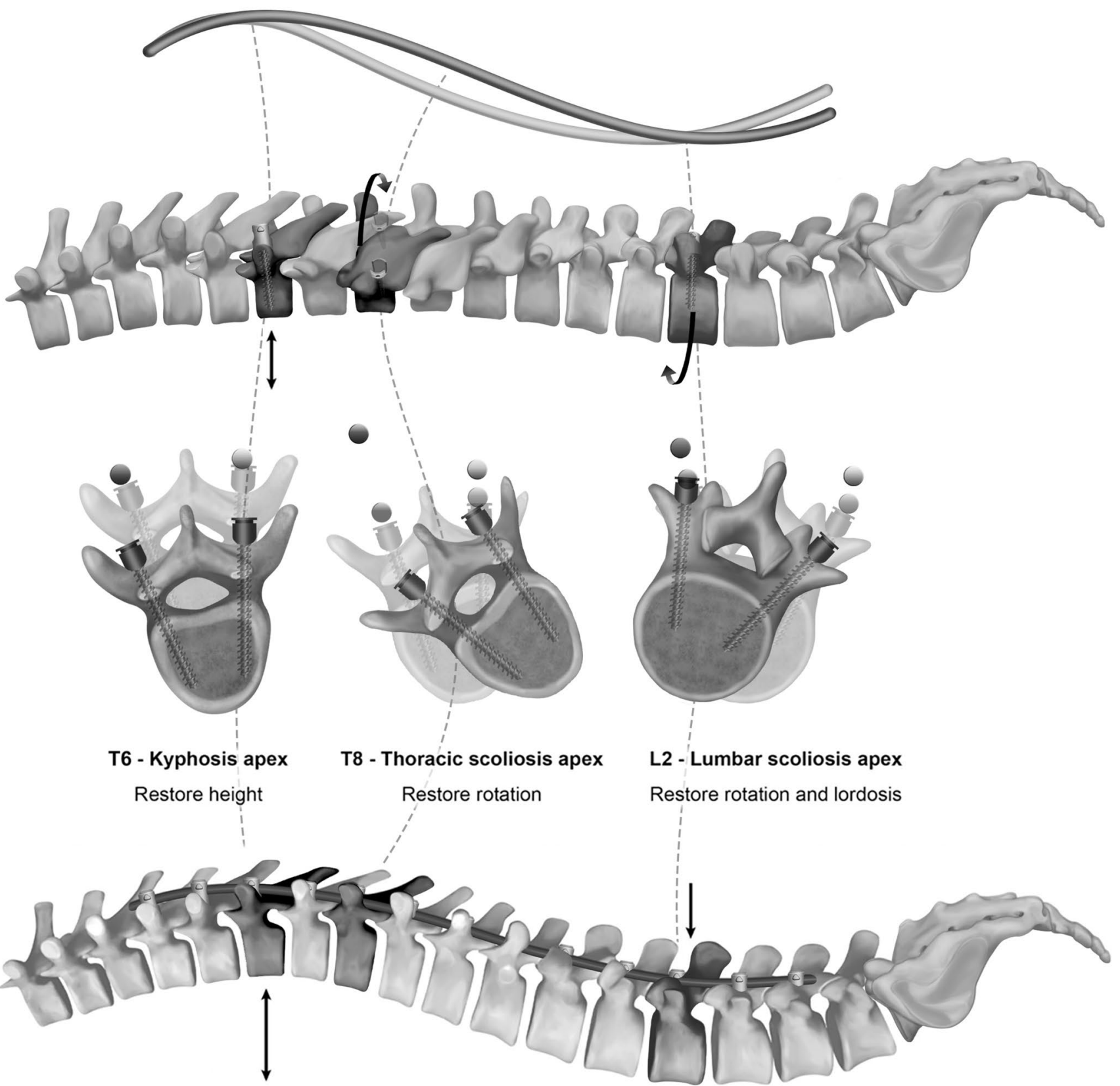

Fig. 1 Surgical technique. The apex of the scoliotic curve and the apex of the desired thoracic kyphosis are determined, and the rods are asymmetrically moulded accordingly. In detail, at the desired kyphosis apex, both the rods are over-shaped without height differences between the two sides, in order to obtain a prevalent lifting effect and restore kyphosis; on the contrary, at the apex of the thoracic curve, the rod in concavity is over-shaped and the rod in convexity is under- shaped with high height difference between the two sides, in order to obtain a prevalent derotating and lifting effect. At the apex of the lumbar curve, the rod in concavity is over-shaped and the rod in convexity is under-shaped, with low height difference between the two sides, to obtain a derotating and a lowering effect and restore lumbar lordosis rods was performed dissipating the corrective forces over all the instrumented levels, especially at the apex of the concavity, where the distance between the tulips and the rod is maximal, as well as the mechanical stresses at the screw-bone interface. When the distance between the rod and the tulips was considered too high by the Surgeon, with the risk of screw pull-out, rod curvature was slightly reduced using in situ rod benders. Before engaging the rods in the tulips, selective compression and distraction were performed at apical and periapical levels to close gaps at the Ponte osteotomy sites. Final engagement of the rods was then performed. In this phase, if a minimal amount of pull-out was 


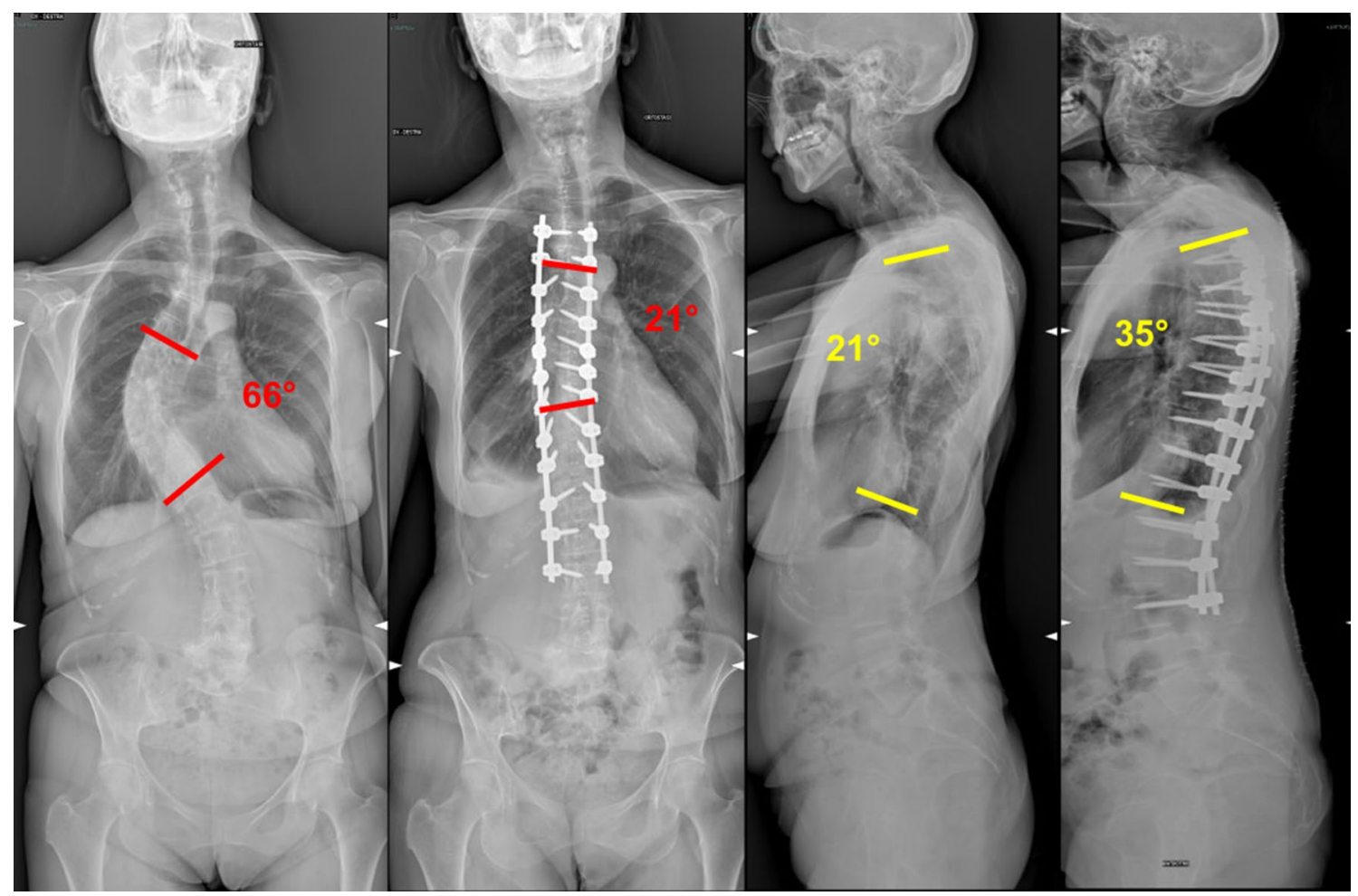

Fig. 2 Clinical case, 67-year-old woman, 29 months follow-up. Thoracic scoliosis with a main curve of $66^{\circ}$ Cobb. T4-L3 fusion was performed, with three periapical Ponte osteotomies. Cobb's angle decreased to $21^{\circ}$ and Thoracic Kyphosis increased to $35^{\circ}$

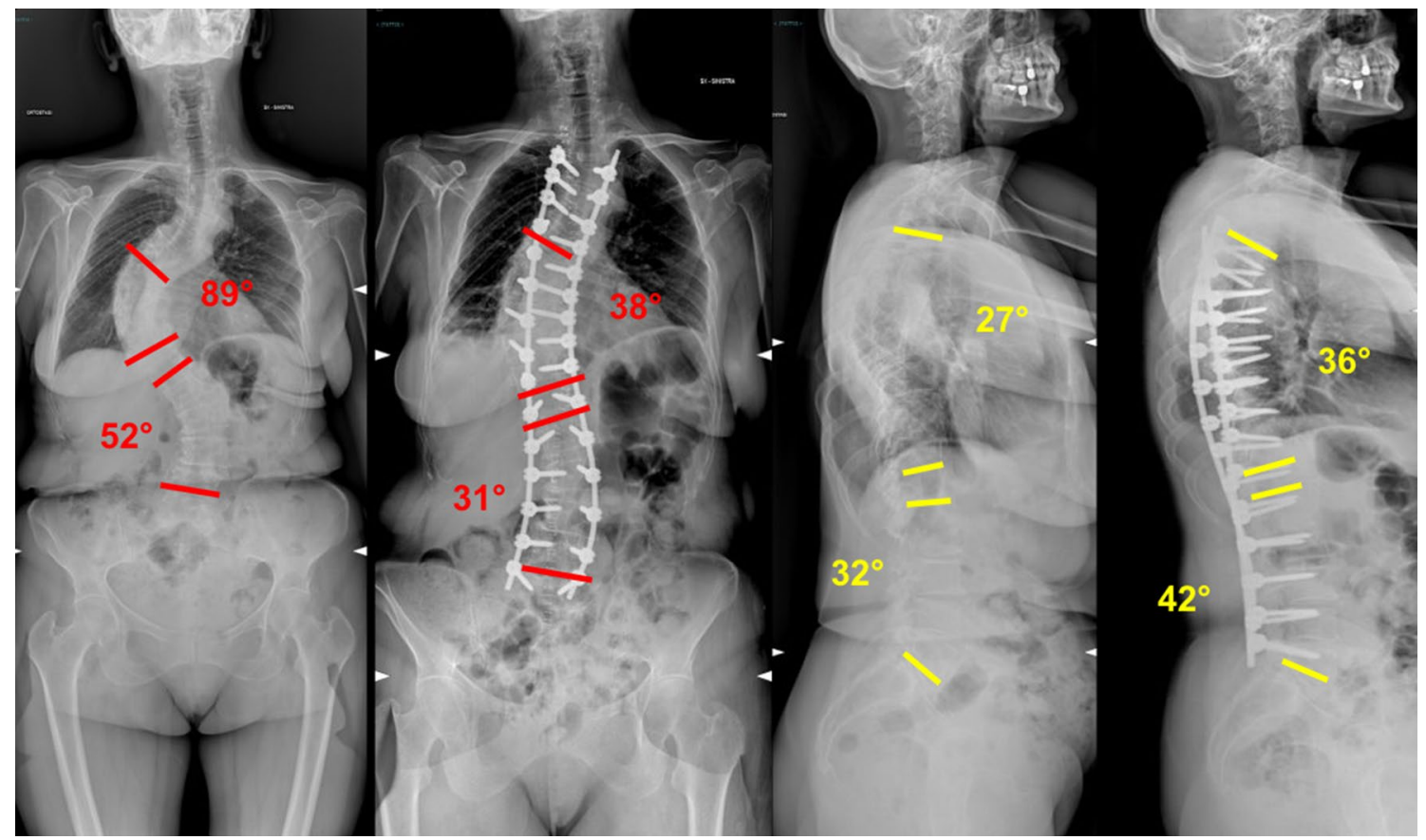

Fig. 3 Clinical case, 65-year-old woman, 24 months follow-up. Double major scoliosis with main thoracic (MT) curve of $83^{\circ}$ and lumbar curve (L) of $52^{\circ}$. T3-L5 fusion was performed, with five periapical
Ponte osteotomies. Cobb's angle of the MT curve decreased to $38^{\circ}$ and of the L curve decreased to $31^{\circ}$; thoracic kyphosis increased to $36^{\circ}$ and lumbar lordosis to $42^{\circ}$ 


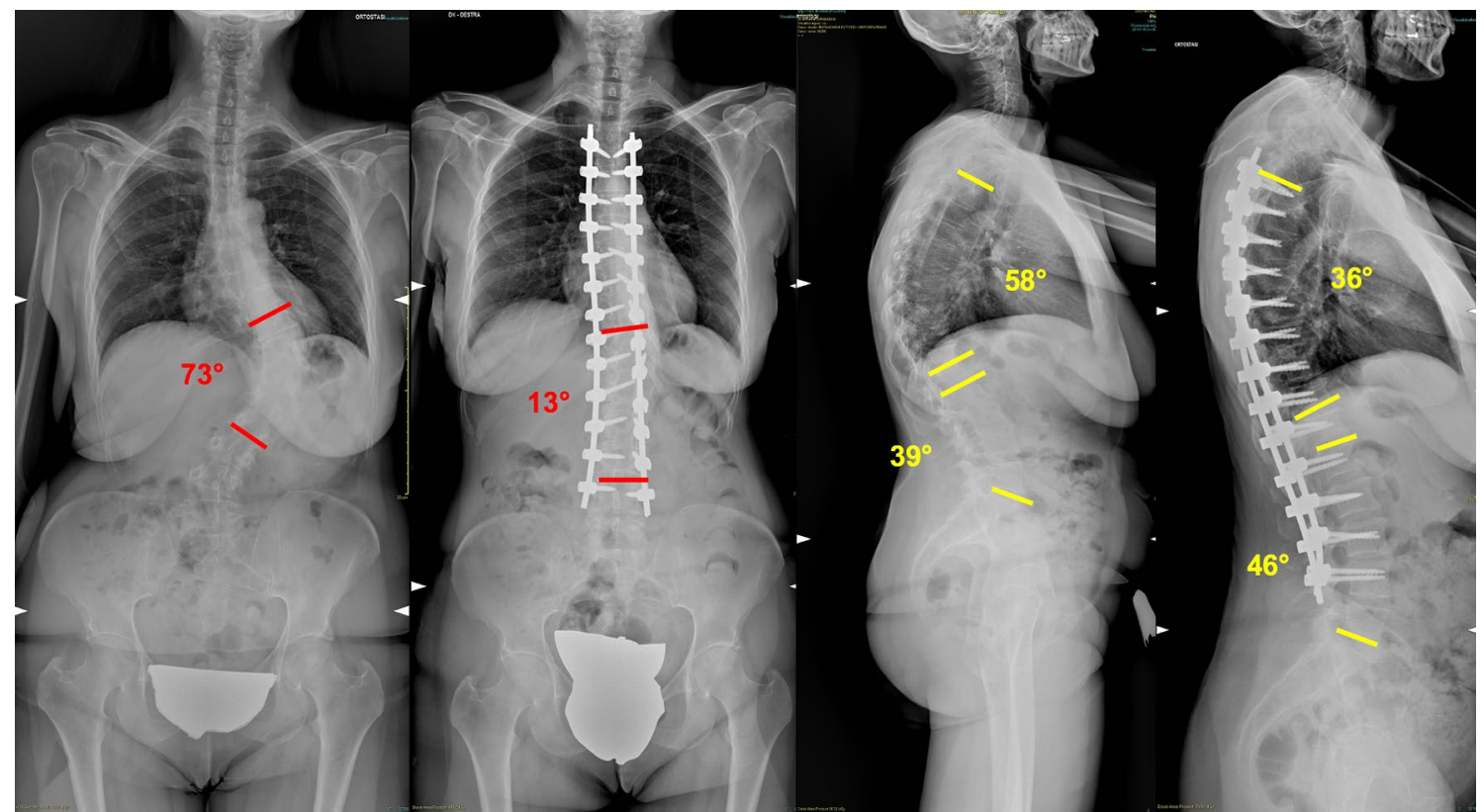

Fig. 4 Clinical case, 53-year-old woman, 27 months follow-up. Thoraco-lumbar scoliosis with main curve of $73^{\circ}$ and thoracic hyperkyphosis $\left(58^{\circ}\right)$. T4-L4 fusion was performed, with five periapical

observed at the apical and periapical levels in concavity, it was considered clinically irrelevant. In situ rod benders were used to complete coronal correction if needed. An extensive decortication of the posterior elements of the instrumented vertebrae was performed. Subfascial drain was placed, and standard suture was performed.

Early mobilization out of bed started on post-operative day 1 . For the first 6 weeks after surgery, a thoracic lumbar sacral orthosis (TLSO) to restrict spinal movements and facilitate initial bone graft fusion was prescribed.

\section{Patient's characteristics}

Forty patients ( 8 males and 32 females) were included, with a follow-up of $2.9 \pm 0.4$ (range 2-3.5). The average age was $51.4 \pm 6$ (range 41-63). Patient's characteristics are summarized in Table 1.

\section{Statistical analysis}

Parametric test was used to compare samples in case of continuous variables, normal distribution and appropriate numerousness. The Shapiro-Wilk test was used to verify normal distribution. The Levene test was used to evaluate homogeneity of the variances. As parametric test, we used two-tailed student $t$ test to compare the average of the variables for homoscedastic paired groups. As nonparametric test, we used the two-tailed Wilcoxon signed-rank test for paired group. Continuity correction was applied in case of
Ponte/Smith-Petersen osteotomies. Cobb's angle decreased to $13^{\circ}$ and thoracic kyphosis decreased to $36^{\circ}$ and lumbar lordosis to $46^{\circ}$

Table 1 Patient's characteristics

\begin{tabular}{ll}
\hline Patients $n$ & 40 (8 males, 32 females) \\
Average age (years) & $51.4 \pm 6$ (range 41-63) \\
Curve type & 27 thoracic, 9 thoraco-lumbar/ \\
& lumbar, 4 double major \\
Coronal flexibility & $13.3 \% \pm 4.6$ \\
Average fused levels & $11.6 \pm 1.4$ (range 9-14) \\
Average pedicle screws implanted & $22.7 \pm 2.7$ (range 17-28) \\
Screw density & $98.1 \% \pm 2.7 \%$ (range 91.7-100\%) \\
Ponte osteotomies & $4.5 \pm 1$ (range 3-6) \\
Average surgical time (mins) & $283.4 \pm 56.3$ \\
Average blood loss (mL) & $1045 \pm 555.4$ mL \\
Average length of stay (days) & $7.1 \pm 3.4$ (range 5-10) \\
Average follow-up (years) & $2.9 \pm 0.4$ (range 2-3.5) \\
\hline
\end{tabular}

discrete distribution. $P$-values $<0.05$ were considered to be significant. SPSS 17.0 statistical analysis software (SPSS Inc., Chicago, Illinois, USA) was used to perform statistical analysis.

\section{Results}

Average surgical time was $283.4 \pm 56.3 \mathrm{~min}$, and average blood loss was $1045 \pm 555.4 \mathrm{~mL}$ (Table 1). Intra-operatively, the surgical planning regarding fusion area was respected in all the cases with no need to extend the instrumentation proximally or distally for screws pull-out during corrective 
manoeuvre at the most cephalad and caudal levels. Less than $5 \mathrm{~mm}$ screw pull-out at the periapical area happened in four cases at the end of the corrective manoeuvre, during the final seating of the rod in the tulips: in two cases, it involved two screws at the concavity apex in a thoracic curve, in the remaining two cases it involved only one screw.

Patients were discharged after an average length of stay of 7 days (range 5-9).

Significant results were achieved on the three planes after surgery (Table 2): the average post-operative Cobb angle decreased by $70.9 \%$ (from $65.0^{\circ} \pm 8.4$ to $18.9^{\circ} \pm 3.9$, $p<0.001)$. On the sagittal plane, post-operative TK increased by $55.8 \%$ (from $23.1^{\circ} \pm 3.6$ to $36.0^{\circ} \pm 3.9$, $p<0.001$ ), while LL increased by $31.6 \%$ (from $29.7^{\circ} \pm 4.3$ to $\left.39.1^{\circ} \pm 4.5, p<0.001\right)$. The average C7PL/CSVL reduced to physiological value of $1.3 \pm 0.5 \mathrm{~cm}(p<0.001)$. No differences were observed in the radiological results between post-operative values and final follow-up.

SRS-22 questionnaire increased in all patients, from a pre-operative value of $2.8 \pm 0.4$ to a mean of $3.8 \pm 0.5$ at last follow-up $(p<0.001)$.

We had four early post-operative deep wound infections, healed after debridement and implant retention.

At the last follow-up, no cases of progression of the deformity, proximal or distal junction pathology, pull-out of the screws or non-union were recorded.

\section{Discussion}

$H i$-PoAD technique, although technically demanding, resulted in average operative time and blood loss equal or inferior to the principal case series dealing with AdIS [2, 5, $13,20,21]$. It also proved to be efficient in respect surgical planning, with no need to extent the fusion area due to screw pull-out at the most cephalad and caudal levels, meaning that the procedure is really effective in dissipating corrective forces avoiding intra-operative mechanical complications. In the four cases in which a minimal pull-out was observed at periapical levels, no mechanical complications nor correction loss was observed up to final follow-up.

The triplanar correction rate of the technique proved to be really efficient with excellent correction rates in terms of coronal and sagittal correction (70.1\% correction of the main curve, $57.9 \%$ increase in TK and 32\% increase in LL). Indeed, the obtained $70.1 \%$ of coronal correction is superior to the higher percentage of correction observed in the literature [2, 5, 13, 20]. Only Zhu et al. [21] reported similar correction rates (up to $71 \%$ ) but in younger patients (22.2 years old) with flexible curves (curve flexibility of $48 \%$ ).

$\mathrm{Hi}$-PoAD proved to be really effective also in restoring an adequate sagittal and coronal balance (with SVA improvement of $42.5 \%$ and C7PL/CSVL reduction of $40.9 \%$ ), which

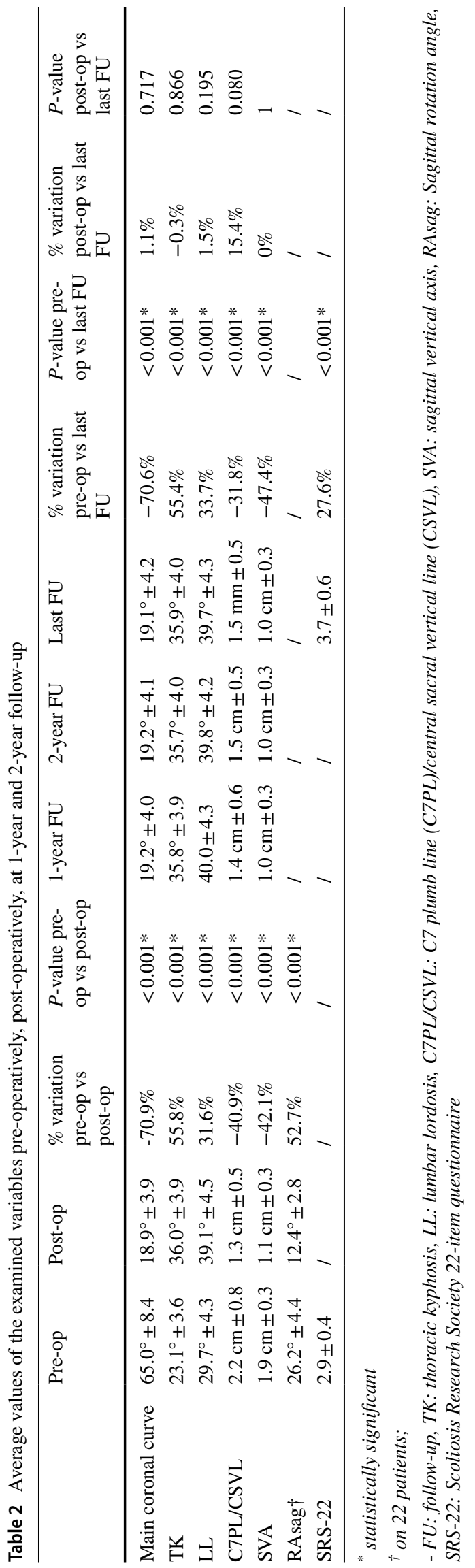


is a mainstream in treatment of AdIS given the low compensation potential of the residual mobile segments after fusion. It is also important to highlight the low complication rate experienced (10\%) with respect to the $25-29 \%$ range reported by other case series dealing with AdIS [5, 20].

The rationale of $\mathrm{Hi}-\mathrm{PoAD}$ technique is to combine different surgical strategies to dissipate corrective forces over several levels, in order to reduce the mechanical stress at the screw-bone interface in patients affected by rigid AdIS and older than 40 years, therefore, with a high risk of fixation failure due to excessive forces needed to obtain correction.

A very high screw density is mandatory to avoid mechanical complications during the corrective manoeuvre; it is crucial especially at periapical levels of the curve, both to dissipate the corrective forces at the level of the most rigid and rotated segments and to obtain a segmental control of each space in which Ponte osteotomy is performed.

The use of the original Ponte osteotomy for the treatment of rigid AdIS has been well documented in the literature [10-13]. Clinical and cadaver studies have shown marked segmental flexibility in all three planes produced by Ponte osteotomy [22-24]. Therefore, the apical and the first cephalad and caudal segments were selected as the candidate region for Ponte osteotomy in all cases. The need for additional osteotomies should be carefully evaluated to avoid unnecessary blood loss and prolonged surgical times [23]. The authors performed additional osteotomies only in curves larger than $70^{\circ}$.

Another issue is represented by the corrective manoeuvre. The majority of the studies reporting outcomes after AdIS focuses on osteotomies, without extensive description of the applied manoeuvre $[2,5,13,20,21]$. A combined manoeuvre, mixing column translation over differently moulded rods simultaneously applied, DVR and selective compression and distraction at periapical levels are fundamental in author's opinion to obtain satisfactory results. The translation manoeuvre is extremely effective in restoring an adequate sagittal balance with a high potential in restoring thoracic kyphosis and lumbar lordosis [14-16]. In addition, the translation is proved to be efficient in raising the apex of thoracic kyphosis in a more cephalad position $[16,25]$, and this finding is proved to be really useful especially when dealing with thoracic and thoraco-lumbar curves in which the kyphosis apex is usually lowered with relevant clinical consequences. The translation manoeuvre is responsible for a certain amount of derotation-given the rods height difference at the curve apex-but DVR is applied at the same time and at the same levels, in order to further reduce the forces over the screws, enhancing translation and promoting a better axial correction with a remarkable outcome in terms of rib hump reduction [16, 25]. Moreover, the simultaneous application of the rods, although technically demanding, is an important factor for the success of the technique: asynchronous application of the rods usually leads to the application of the second rod with a neutralization task or, even worse, when the second rod is applied with corrective purpose, the corrective forces act against the restrain offered by the engaged rod with high risk of mechanical complications. Conversely, the two simultaneously applied rods act in a synergic way, coupling anchor points acting both in concavity and in convexity, optimizing the translation and the direct vertebral rotation avoiding the risk of exerting opposite forces.

The small sample size and the retrospective design are clear limitations of the study, but the homogeneous cohort of patients treated and the presence of only one surgeon reduce variability and represent remarkable strengths of the current paper.

\section{Conclusions}

In conclusion, although technically demanding, $H i-P O A D$ is a combined technique which, with its high corrective potential on coronal, axial and sagittal plane alongside a low complication rate, may be particularly useful for rigid Adult Idiopathic Scoliosis.

Funding Open access funding provided by Alma Mater Studiorum Università di Bologna within the CRUI-CARE Agreement.

\section{Declarations}

\section{Conflict of interests None.}

Open Access This article is licensed under a Creative Commons Attribution 4.0 International License, which permits use, sharing, adaptation, distribution and reproduction in any medium or format, as long as you give appropriate credit to the original author(s) and the source, provide a link to the Creative Commons licence, and indicate if changes were made. The images or other third party material in this article are included in the article's Creative Commons licence, unless indicated otherwise in a credit line to the material. If material is not included in the article's Creative Commons licence and your intended use is not permitted by statutory regulation or exceeds the permitted use, you will need to obtain permission directly from the copyright holder. To view a copy of this licence, visit http://creativecommons.org/licenses/by/4.0/.

\section{References}

1. Aebi M (2005) The adult scoliosis. Eur Spine J 14(10):925-948. https://doi.org/10.1007/s00586-005-1053-9

2. Chan CYW, Gani SMA, Chung WH, Chiu CK, Hasan MS, Kwan MK (2021) (2021) A comparison between the perioperative outcomes of female adolescent idiopathic scoliosis (AIS) versus adult idiopathic scoliosis (AdIS) following posterior spinal fusion: a propensity score matching analysis involving 425 patients. Glob 
Spine J. 2:2192568221991510. https://doi.org/10.1177/21925 68221991510

3. Deviren V, Berven S, Kleinstueck F, Antinnes J, Smith JA, Hu SS (2002) Predictors of flexibility and pain patterns in thoracolumbar and lumbar idiopathic scoliosis. Spine (Phila. Pa. 1976), 27(21), 2346-2349. https://doi.org/10.1097/00007632-200211010-00007;

4. Bradford DS, Tay BKB, Hu SS (1999) Adult scoliosis: Surgical indications, operative management, complications and outcomes. Spine (Phila. Pa. 1976). 24:2617-2629. https://doi.org/10.1097/ 00007632-199912150-00009

5. Takahashi S, Delécrin J, Passuti N (2002) Surgical treatment of idiopathic scoliosis in adults: An age-related analysis of outcome. Spine (Phila Pa 1976) 27:1742-1748. https://doi.org/10.1097/ 00007632-200208150-00011

6. Rushton PRP, Elmalky M, Tikoo A et al (2016) The effect of metal density in thoracic adolescent idiopathic scoliosis. Eur Spine J 25:3324-3330. https://doi.org/10.1007/s00586-015-4335-x

7. Mac-Thiong JM, Ibrahim S, Parent S, Labelle H (2017) Defining the number and type of fixation anchors for optimal main curve correction in posterior surgery for adolescent idiopathic scoliosis. Spine J 17:663-670. https://doi.org/10.1016/j.spinee.2016.11.012

8. Larson AN, Polly DW, Diamond B, et al (2014) Does higher anchor density result in increased curve correction and improved clinical outcomes in adolescent idiopathic scoliosis? Spine (Phila $\mathrm{Pa}$ 1976) 39:571-578. https://doi.org/10.1097/BRS.0000000000 000204

9. Ketenci IE, Yanik HS, Demiroz S, et al (2016) Three-dimensional correction in patients with lenke 1 adolescent idiopathic scoliosis comparison of consecutive versus interval pedicle screw instrumentation. Spine (Phila Pa 1976) 41(2):134-138. https://doi.org/ 10.1097/BRS.0000000000001182

10. Ponte A, Orlando G, Siccardi GL (2018) The True Ponte Osteotomy: By the One Who Developed It. Spine Deform 6(1):2-11. https://doi.org/10.1016/j.jspd.2017.06.006

11. Samdani AF, Bennett JT, Singla AR et al (2015) Do Ponte osteotomies enhance correction in adolescent idiopathic scoliosis? An analysis of 191 Lenke 1A and 1B curves. Spine Deform 3(5):483488. https://doi.org/10.1016/j.jspd.2015.03.0022015

12. Zhang Y, Tao L, Hai Y, et al (2019) One-stage posterior multiplelevel asymmetrical ponte osteotomies versus single-level posterior vertebral column resection for severe and rigid adult idiopathic scoliosis: a minimum 2-year follow-up comparative study. Spine (Phila Pa 1976) 44(20):E1196-E1205. https://doi.org/10.1097/ BRS.0000000000003101

13. Zhang Y, Hai Y, Tao L, Yang J, Zhou L, Yin P, Pan A, Zhang Y, Liu C (2019) Posterior multiple-level asymmetrical ponte osteotomies for rigid adult idiopathic scoliosis. World Neurosurg 127:e467-e473. https://doi.org/10.1016/j.wneu.2019.03.173

14. Clement JL, Chau E, Geoffray A, Suisse G (2014) Restoration of thoracic kyphosis by simultaneous translation on two rods for adolescent idiopathic scoliosis. Eur Spine J 23(Suppl 4):S438-S445. https://doi.org/10.1007/s00586-014-3340-9

15. Wang X, Boyer L, Le Naveaux F et al (2016) How does differential rod contouring contribute to 3-dimensional correction and affect the bone-screw forces in adolescent idiopathic scoliosis instrumentation? Clin Biomech 39:115-121. https://doi.org/10. 1016/j.clinbiomech.2016.10.002

16. Faldini C, Perna F, Geraci G, et al (2018) Triplanar correction of adolescent idiopathic scoliosis by asymmetrically shaped and simultaneously applied rods associated with direct vertebral rotation: clinical and radiological analysis of 36 patients. Eur Spine J 27, Suppl 2:165-174. https://doi.org/10.1007/s00586-018-5595-z. Erratum in: Eur Spine J. 2018 Oct 31.

17. Son SM, Choi SH, Goh TS et al (2019) Efficacy and safety of direct vertebral rotation in the surgical correction of scoliosis: a meta-analysis. World Neurosurg 124:e641-e648. https://doi.org/ 10.1016/j.wneu.2018.12.170

18. Lenke LG, Betz RR, Harms J, Bridwell KH, Clements DH, Lowe TG, Blanke K (2001) Adolescent idiopathic scoliosis: a new classification to determine extent of spinal arthrodesis. J Bone Joint Surg Am 83(8):1169-1181

19. Watanabe K, Lenke LG, Matsumoto M, Harimaya K, Kim YJ, Hensley M, Stobbs G, Toyama Y, Chiba K (2010) A novel pedicle channel classification describing osseous anatomy: how many thoracic scoliotic pedicles have cancellous channels? Spine (Phila Pa 1976). 35(20):1836-42. https://doi.org/10.1097/BRS.0b013e3181 d3cfde

20. Lonner BS, Ren Y, Bess S et al (2019) Surgery for the adolescent idiopathic scoliosis patients after skeletal maturity: early versus late surgery. Spine Deform 7(1):84-92. https://doi.org/10.1016/j. jspd.2018.05.012

21. Zhu F, Bao H, Yan P, et al. (2017) Comparison of surgical outcome of adolescent idiopathic scoliosis and young adult idiopathic scoliosis: a match-pair analysis of 160 patients. Spine (Phila Pa 1976). 42 (19):E1133-E1139. https://doi.org/10.1097/BRS.00000 00000002106

22. Sangiorgio SN, Borkowski SL, Bowen RE, Scaduto AA, Frost NL, Ebramzadeh E (2013) Quantification of increase in three-dimensional spine flexibility following sequential Ponte osteotomies in a cadaveric model. Spine Deform 1(3):171-178. https://doi.org/ 10.1016/j.jspd.2013.01.006

23. Shah SA, Dhawale AA, Oda JE et al (2013) Ponte osteotomies with pedicle screw instrumentation in the treatment of adolescent idiopathic scoliosis. Spine Deform 1(3):196-204. https://doi.org/ 10.1016/j.jspd.2013.03.002

24. Halanski MA, Cassidy JA (2013) Do multilevel ponte osteotomies in thoracic idiopathic scoliosis surgery improve curve correction and restore thoracic kyphosis? J Spinal Disord Tech 26(5):252255. https://doi.org/10.1097/BSD.0b013e318241e3cf

25. Faldini C, Perna F, Chehrassan M et al (2016) Simultaneous double rod and en-bloc direct vertebral rotation technique for correction of main thoracic adolescent idiopathic scoliosis: retrospective analysis of 14 cases. J Biol Regul Homeost Agents 30(4 Suppl 1):181-186

Publisher's Note Springer Nature remains neutral with regard to jurisdictional claims in published maps and institutional affiliations. 